\title{
EDITORIAL
}

\section{Arousal in the sleep apnoea syndrome: a mixed blessing?}

\author{
W.T. McNicholas
}

Obstructive sleep apnoea syndrome (OSAS) is characterized by recurring episodes of upper airway (UA) obstruction with consequent transient asphyxia. Termination of apnoea is usually associated with brain arousal [1, 2], and therefore, the arousal response is important for survival of the affected patient. However, the physiological events that surround the arousal response may also have adverse consequences which may contribute to the pathophysiology of the syndrome, firstly by contributing to the prominent symptom of daytime sleepiness and secondly by predisposing to further UA obstruction and thus setting the stage for repetitive apnoeas. The present issue of the Journal contains two papers [3, 4] which address different aspects of the arousal response and its consequences, and add to our understanding of this central event in the pathophysiology of OSAS.

The repeated arousals that occur in patients with OSAS usually result in sleep fragmentation, poor sleep quality and diminished amounts of slow wave and rapid eye movement (REM) sleep. Patients with OSAS are usually unaware of such arousals, but the resulting deterioration in sleep quality is likely to contribute significantly to the symptom of daytime sleepiness which is a central clinical feature of the condition. The arousal response does not usually lead to complete awakening, but rather causes lightening of sleep, with a shift from a deeper sleep stage to a lighter sleep stage. Alternatively, there may be no formal change in sleep stage by conventional definition, but short bursts of alpha waves may be seen at the termination of each apnoea. These sleep stage/state changes lead to sleep fragmentation, which in turn can worsen the underlying OSAS [5]. Thus, recurring arousals are likely to play an important role in one of the most debilitating clinical features of OSAS.

However, the extent of the contribution of arousal to daytime sleepiness is debated, and the paper by KInGSHOTT $e t$ al. [3] shows only a weak but nonetheless significant relationship between conventional arousal indices and both subjective and objective measures of daytime sleepiness and alertness. The authors findings are in agreement with some previous reports but contrast with other reports that have shown a strong relationship between arousal frequency and sleepiness. The contrasting findings of previous reports are extensively discussed in their paper.

One of the major problems in assessing the role of arousal in the pathophysiology of OSAS is that, at present, there is no universally accepted definition of arousal, and this largely relates to the limitations of the standard RECHTSCHAFFEN and KALES [6] criteria which are currently the gold

Correspondence: W.T. McNicholas, Dept of Respiratory Medicine, St. Vincent's University Hospital, Elm Park, Dublin 4, Ireland. Fax: 353 12697949 standard for staging sleep. The definition of arousal agreed by the American Sleep Disorders Association (ASDA) is the one most widely used [7] but is nonetheless recognized to have considerable limitations, and may not adequately reflect the true degree of sleep fragmentation produced by recurring apnoeas. For example, spectral analysis of the electroencephalogram (EEG) has demonstrated that the median EEG frequency rises from the first half to the second half of an apnoea suggesting that there is evidence of partial arousal developing from much earlier on during the course of an apnoea [8]. Furthermore, another recent report by BeNNETT et al. [9] has demonstrated that body movement index and the variability in EEG sleep depth quantified from computerized EEG analysis were better predictors of nasal continuous positive airway pressure (CPAP) responsive subjective and objective sleepiness than arousal frequency as defined by the ASDA criteria. These findings indicate that conventional polysomnography may not provide the best measures of sleep disruption associated with OSAS, and different methods of analysing sleep, sleep fragmentation, and arousal are probably needed to evaluate patients with OSAS optimally.

The subject is further complicated by the observation that not all apnoeas and hypopnoeas are terminated by cortical arousals, and that fragmenting sleep in normal subjects sufficient to produce transient increases in arterial blood pressure or increases in heart rate without visible EEG arousal can make these subjects sleepier and impair their mood, similar to patients with OSAS [10]. Apnoeas that do not result in a definite arousal have been shown to have the same duration as apnoeas with arousal, along with similar peak pleural pressures, increases in blood pressures and carbon dioxide tension $\left(\mathrm{PCO}_{2}\right)$, at apnoea termination [8]. This similarity has been explained by suggesting that arousal responses are mediated by brain stem mechanisms, with their cortical effects being a less consistent finding at the resumption of respiration [8]. Nevertheless, it has also been shown that the frequency of movement arousals (EEG arousal accompanied by an increase in submental electromyogram (EMG) is significantly higher in patients with OSAS than normals, nonapnoeic snorers, and patients with chronic obstructive pulmonary disease (COPD) or neuromuscular disorders, and correlates with apnoea-hypopnoea index (AHI) and loss of both slowwave and REM sleep) [11]. Thus, the precise definition of arousal, and its role in quantifying OSAS severity, remains an area of much debate.

Arousal may also contribute to the development of further obstructive apnoea, because of the associated changes in gas exchange. Studies involving transient UA occlusion in normal subjects have demonstrated that when the occlusion is associated with arousal, hyperventilation and a fall 
in end-tidal $\mathrm{PCO}_{2}\left(P \mathrm{ET}, \mathrm{CO}_{2}\right)$ follow relief of the occlusion, whereas if no arousal occurs, hyperventilation is obtunded and $P$ ET, $\mathrm{CO}_{2}$ rises. This post-apnoeic hyperventilation and fall in $\mathrm{PCO}_{2}$ associated with arousal can reduce respiratory drive, and the resulting reduced drive to the UA muscles may predispose to further apnoea $[12,13]$, and a repetitive cycle of recurring apnoeas may ensue.

The mechanisms by which the various features of obstructive apnoea, namely inspiratory efforts against an occluded airway, hypoxia, and hypercapnia, lead to arousal from sleep are not fully understood. Furthermore, nonrespiratory stimuli can also affect apnoea duration, an effect that does not necessarily required cortical arousal [14]. Increasing ventilatory effort appears to contribute to arousal, possibly mediated by mechanoreceptor feedback from respiratory muscles and/or from pressure-sensitive mechanoreceptors in the UA $[15,16]$. Hypoxaemia is one of the most obvious consequences of obstructive sleep apnoea (OSA), but its contribution to arousal is uncertain. While animal studies involving carotid body denervation [17] support an important role for hypoxaemia in the arousal response, hypoxaemia has been shown to correlate poorly with arousal in normal humans [18] and in patients with COPD [19]. Hypercapnia, although less obvious than hypoxaemia in association with OSA, appears to be a more potent stimulus to arousal [20-22]. Overall, increasing ventilatory effort may be the most important stimulus to arousal from sleep, and the stimulus to arousal from hypoxia and hypercapnia may be mediated principally through stimulating an increased ventilatory effort [16].

The cumulative effects of repetitive UA occlusions may also have an effect on the arousal response, across the same night and over successive nights. The report of SFORZA et al. [4] in this issue offers important information in this regard, and indicates that the progressive rise in apnoea duration reported by others $[23,24]$ relates more to an increase in the arousal threshold caused by recurrent apnoeas rather than to changes in chemosensitivity or UA resistance. Other workers have demonstrated that the rate of increase in transdiaphragmatic pressure $(P \mathrm{di})$ remains the same across the night, but the $P$ di at apnoea termination increases significantly as a result of longer apnoeas $[24,25]$. The nadir in arterial oxygen saturation remains the same, so that a progressive decline in the arousal response to neural stimuli generated during obstructed inspiratory efforts appears to play a major role in apnoea lengthening across the night [25]. A blunting of the airway receptors secondary to airway oedema could also raise the arousal threshold. Studies using topical oropharyngeal anaesthesia in sleeping subjects with OSAS support this hypothesis of attenuation of UA mechanoreceptor function throughout the night, and is thought to result from repeated trauma to pharyngeal tissues as a consequence of UA vibration associated with snoring and recurring UA obstruction [24]. The effects of sleep deprivation and sleep fragmentation may interfere with arousal responses, res-ulting in longer and more frequent apnoeas, more marked $\mathrm{O}_{2}$ desaturations and more negative inspiratory effort at arousal [26-29]. Other factors such as recurrent hypoxaemia or habituation to a repeated stimulus could also contribute [27].

The above considerations clearly indicate that while arousal is an important protective mechanism, there are adverse consequences which may contribute both to the pathophysiology and clinical manifestations of obstructive sleep apnoea syndrome. These considerations raise the question of possible manipulation of the arousal response to maximize the beneficial effects related to facilitating resumption of airflow, but minimize the adverse consequences related to sleep fragmentation and post-apnoeic hyperventilation. These latter effects appear to relate more to cortical than brainstem arousal, and raise the possibility that pharmacological intervention designed to blunt cortical arousal but not interfere with brainstem arousal might benefit the syndrome.

\section{References}

1. Remmers JE, DeGroot WJ, Sauerland FK, Anch AM. Pathogenesis of upper airway occlusion during sleep. $J$ Appl Physiol 1978; 44: 931-938.

2. Issa FG, Sullivan CE. Upper airway closing pressures in obstructive sleep apnea. J Appl Physiol 1984; 57: 520527.

3. Kingshott RN, Engleman HM, Deary IH, Douglas NJ. Does arousal frequency predict daytime function? Eur Respir J 1998; 12: 1264-1270.

4. Sforza E, Krieger J, Petiau C. Nocturnal evolution of respiratory effort in obstructive sleep apnoea syndrome: influence on arousal threshold. Eur Respir J 1998; 12: 1257-1263.

5. Guilleminault C, Rosekind M. The arousal threshold: sleep deprivation, sleep fragmentation, and obstructive sleep apnea syndrome. Bull Eur Physiopathol Respir 1981; 17: 341-349.

6. Rechtschaffen A, Kales A. A manual of standardised terminology, techniques and scoring system for sleep stages in human subjects. Washington DC, National Institutes of Health, 1968; publication No. 204.

7. Sleep disorders atlas task force of the American Sleep Disorders Association, Guilleminault C, Chairman. EEG arousals: scoring and examples. Sleep 1992; 15: 174-184.

8. Rees K, Spence DPS, Earis JE, Calverley PMA. Arousal responses from apneic events during non-rapid-eyemovement sleep. Am J Respir Crit Care Med 1995; 152: 1016-1021.

9. Bennett LS, Langford BA, Stradling JR, Davies RJO. Sleep fragmentation indices as predictors of daytime sleepiness and nCPAP response in obstructive sleep apnea. Am J Respir Crit Care Med 1998; 158: 778-786.

10. Martin SE, Wraith PK, Deary IJ, Douglas NJ. The effect of nonvisible sleep fragmentation on daytime function. Am J Respir Crit Care Med 1997; 155: 1596-1601.

11. Collard P, Dury M, Delguste P, Aubert G, Rodenstein DO. Movement arousals and sleep-related disordered breathing in adults. Am J Respir Crit Care Med 1996; 154: 454-459.

12. Deegan PC, McNicholas WT. Pathophysiology of obstructive sleep apnoea. Eur Respir J 1995; 8: 1161-1178.

13. Berssenbrugge A, Dempsey J, Iber C, Skatrud J, Wilson P. Mechanisms of hypoxia-induced periodic breathing during sleep in humans. J Physiol 1983; 353: 507-526.

14. Basner RC, Önal E, Carley DW, Stepanski EJ, Lopata M. Effect of induced transient arousal on obstructive apnea duration. J Appl Physiol 1995; 78: 1469-1476.

15. Kimoff RJ, Cheong TH, Olha AE, et al. Mechanisms of apnea termination in obstructive sleep apnea: role of chemoreceptor and mechanoreceptor stimuli. Am J Respir Crit Care Med 1994; 149: 707-714. 
16. Gleeson K, Zwillich CW, White DP. The influence of increasing ventilatory effort on arousal from sleep. Am Rev Respir Dis 1990; 142: 295-300.

17. Bowes G, Townsend ER, Kozar LF, Bromley SM, Phillipson EA. Effect of carotid body denervation on arousal response in sleep dogs. J Appl Physiol 1981; 51: 4045.

18. Douglas NJ, White DP, Weil JV, et al. Hypoxic ventilatory response decreases during sleep in normal men. $\mathrm{Am}$ Rev Respir Dis 1982; 125: 286-289.

19. Fleetham J, West P, Mezon B, Conway W, Roth T, Kryger M. Sleep, arousals, and oxygen desaturation in chronic obstructive pulmonary disease. The effect of oxygen therapy. Am Rev Respir Dis 1982; 126: 429-433.

20. Douglas NJ, White DP, Weil JV, Pickett CK, Zwillich CW. Hypercapnic ventilatory response in sleeping adults. Am Rev Respir Dis 1982; 125: 758-762.

21. Berthon-Jones M, Sullivan CE. Ventilation and arousal responses to hypercapnia in normal sleeping humans. $J$ Appl Physiol 1984; 54: 59-67.

22. Hedemark LL, Kronenberg RS. Ventilatory and heart rate responses to hypoxia and hypercapnia during sleep in adults. J Appl Physiol 1982; 53: 307-312.

23. Charbonneau M, Marin JM, Olha A, Kimoff RJ, Levy RD, Cosio MG. Changes in obstructive sleep apnea char- acteristics through the night. Chest 1994; 106: 16951701.

24. Cala SJ, Sliwinski P, Cosio MG, Kimoff RJ. Effect of topical upper airway anesthesia on apnea duration through the night in obstructive sleep apnea. J Appl Physiol 1996; 81: 2618-2626.

25. Montserrat JM, Kosmas EN, Cosio MG, Kimoff RJ. Mechanism of apnea lengthening across the night in obstructive sleep apnea. Am J Respir Crit Care Med 1996; 154: 988-993.

26. O'Donnell CP, King ED, Schwartz AR, Smith PI, Robotham JL. Effect of sleep deprivation on responses to airway obstruction in the sleeping dog. J Appl Physiol 1994; 77: 1181-1188.

27. Berry RB, Kouchi KG, Der DE, Dickel MJ, Light RW. Sleep apnea impairs the arousal response to airway occlusion. Chest 1996; 109: 1490-1496.

28. Persson HE, Svanborg E. Sleep deprivation worsens obstructive sleep apnea. Comparison between diurnal and nocturnal polysomnography. Chest 1996; 109: 645-650.

29. Brooks D, Horner RL, Kimoff RJ, Kozar LF, RenderTeixeira CI, Phillipson EA. Effect of obstructive sleep apnea versus sleep fragmentation on responses to airway occlusion. Am J Respir Crit Care Med 1997; 155: 16091617. 